International Journal of Clinical Therapeutics and Diagnosis (IJCTD)

ISSN 2332-2926

\title{
A Review on Adverse Health Effects of Laboratory Volatile Solvents
}

Review Article

Syamittra $\mathrm{B}^{1}$, Parasuraman $\mathrm{S}^{*}$, Yeng $\mathrm{WY}^{1}$, Ping WY $\mathrm{Wu}^{1}$, Sujithra $\mathrm{J}^{1}$, Kumar $\mathrm{J}^{2}$, Dhanaraj $\mathrm{SA}^{2}$

${ }^{1 *}$ Unit of Pharmacology, Faculty of Pharmacy ,AIMST University, 08100 Bedong, Kedah, Malaysia.

${ }^{2}$ Unit of Pharmaceutical Technology, Faculty of Pharmacy, AIMST University, 08100 Bedong, Kedah, Malaysia.

Abstract
The main objective of this review is to describe the health effects of commonly used laboratory volatile solvents in institutional labo-
ratories. The most commonly used laboratory solvents such as petroleum ether, methanol, diethyl ether, benzene, acetone, mercury,
etc. are having moderate to severe health effects on user. The mode of exposure and duration exposure of volatile solvents has greater
effect on user. In a laboratory, when students / researcher doing experiment unknowingly they are getting exposed with volatile solvents
which has grater health (adverse) effect. The severity of the adverse effect varies based on type of exposure and duration exposure. The
undesired effects of laboratory volatile solvents are sometime irreversible and may cause life-threatening problems.
Keywords: Toxin, petroleum ether, methanol, diethyl ether, benzene, acetone, mercury.

\section{*Corresponding Author:}

S Parasuraman,

Unit of Pharmacology, Faculty of Pharmacy, AIMST University, 08100

Bedong, Kedah, Malaysia.

E-Mail: parasuphd@gmail.com

Received: September 03, 2014

Accepted: September 10, 2014

Published: September 12, 2014

Citation: Syamittra B et al., (2014) A Review on Adverse Health Effects of Laboratory Volatile Solvent. Int J Clin Ther Diagn. 2(5), 59-63. doi: http://dx.doi.org/10.19070/2332-2926-1400012

Copyright: S Parasuraman ${ }^{\odot}$ 2014. This is an open-access article distributed under the terms of the Creative Commons Attribution License, which permits unrestricted use, distribution and reproduction in any medium, provided the original author and source are credited.

\section{Introduction}

Organic solvents are widely used in chemistry/ pharmaceutical laboratory and industries and despite their declining exposure levels, health hazards still exist. The route of exposure of volatile petrochemicals substances is usually through the airways or skin and the hazard effect causes various acute and chronic effects in central nervous system, cardiovascular system, etc. Kaukiainen et al., analyzed the biochemical parameters in 29 solvent exposed workers and they reported the effect of chronic solvent exposure on these subjects. They found multi-systemic effect on solvent and this effect is similarities with those in the metabolic syndrome[1]. In 1994, Lundberg et al., reported the "possible signs of liver dysfunction" in workers who worked in trades for at least 10 years before 1970.[2] Most of researchers using volatile solvent for many of their research and unknowingly people surrounding to the laboratory/ to the reaction place they are inhaling without knowing the health effect of the chemical solvents. The chemical which we are using in laboratory not only dangerous to people who working in the laboratory and also it has effects on our society and our earth. The Bhopal disaster (Bhopal gas tragedy) and Chlorofluorocarbons (CFCs) examples for the effect of laborato- ry gas on society and on our earth respectively. The Bhopal (India) gas tragedy was considered the World's worst industrial disaster occurred on the night of 2-3 December 1984 at Union Carbide India Limited, a pesticide plant in Bhopal. In Bhopal gas tragedy 520,000 people were exposed with methyl isocyanate gas and it caused $>100,000$ permanent injuries, $>2000$ death in first week after disaster and 3,787 total deaths. [3-5] Another best example for effect of laboratory gas on our ecological system is CFCs, and it was developed in 1930's as safe, non-toxic, non-flammable alternative for ammonia for the purposes of air conditioning and cooling units and as aerosol spray propellants prior to the $1970 \mathrm{~s}$. Later CFCs introduced chlorine into the ozone layer and caused damage in ozone layer there by increased the ultraviolet radiation in our ecological system. [6,7] The above discussed few examples are clearly indicating the effects of chemical/ chemical gases on galaxy. The main objective of this review is to discuss the various type of toxins and health effects of commonly used laboratory volatile solvents.

\section{Toxin}

A poison, often times utilized to denote specifically to a protein produced by some higher plants, certain animals and pathogenic bacteria, which is highly toxic for other living organisms. [8] Such substances are differentiated from the simple chemical poisons and vegetable alkaloids by their high molecular weight and antigenicity. Technically, a poison produced by the metabolic attention of a microorganism (such as Clostridium botulinum), an animal (such as snake), or plant (such as nightshade) that, after given in a living organism, is seen as an antigen and the organism produces antibodies as a response. In general, though, the word is utilized as an alternative for a poison or toxicant. "Toxin" is a word that has no commonly accepted meaning in the logical literature.[9]This could be of slight report to the condition powers of Member States unless they come to be obliged to pursue global assistance because of a toxin-warfare attack, whether actual or threatened. It could next be vital to comprehend how toxins are indulged in the Biological and Chemical Armaments Conventions as, to differing degrees, these two global accords are possible sources of such assistance.[10] The 1972 Biological and Toxin Armaments 
Convention covers "toxins whatever their basis or method of production".[11]

\section{Various Toxic Substances}

Herbal Toxins: Herbal medicines have been used world-wide for thousands of years. These herbs mainly originate from plants, minerals and animal products, and may be used either in their primary forms or combined into mixtures. Herbal food supplements and products have increased significantly which results in well-known traditional herbal medicine.[12] However, in developing countries such as Malaysia, Indonesia and Thailand, the toxicity of this product have been considered serious because of increase in consumption in recent years. Hepatotoxicity of main constituents and contamination of raw materials have been found out as few of the major toxic effects of herbal medicine.[13] Contamination of raw materials such as aflatoxin can occur if the medicinal herbs and plants are not fully dried or improperly stored during preparation. In Malaysia and Indonesia, commonly known herbal medicine 'jamu' and 'makjun' are commercially available and consumed regularly to promote health. Herbal medicines can also be made into various preparations such as pills, liquids, etc. It is also can be made commercially available in the form of proprietary medicines. The use of herbal medicine may be different in each culture, individual, society but can be considered as nontoxic and harmless. Even though traditionally, herbs are known to be nontoxic and harmless due to its natural origin but it has both adverse effects and poisonings related with the use of herbal medicines which have been reported commonly in recent years. In daily practice, many herbal poisonings were not diagnosed or treated correctly.[14]

Chemical Toxins: Effort to evaluate the toxicity property of millions of chemicals which have being synthesized yearly should be done.[15] Evaluation of such large volume of toxicity of compounds is the basic importance in both ecosystem and human health.[16] Usually, in silico methods are effective method for virtual screening of unknown molecules even before their synthesis and which is clearly important to complement the experimental approaches for reducing time and cost, and thus accelerating the prioritization of those compounds of interest.[17] However, all these techniques have their inherent limitations in either the predictivity, application domain or even algorithms themselves.[18] More severely, most available toxic data involve diverse kinds of compounds, but are evaluated by a same or similar toxicological endpoint (lethal doses, macroscopic toxicity).[19] This makes the precise prediction of a toxin mechanism from a molecular level is often impossible, let alone to consider the multiple toxin-targets interactions.

Biological Toxins: Most of the food borne pathogens are classified as toxins. Bacterial toxins are the most common toxins especially gram positive bacteria such as Clostridium botulinum, Clostridium perfringens and Staphylococcus aureus.[20-22] Depending upon the stability, the production of bacteria can occur at any stage of food chain and remain biologically active. Namely, toxigenic bacteria are differentiated on the basis that they cause disease by producing toxins in food prior to its ingestion (causing intoxication) or in the intestines of the host (causing toxico-infection). Toxins which share number of similar biological effects and they have required degree of similarity in their chemical properties. [23] These are examples of two toxins, one being established biological hazard, cereulide (produced by Bacillus cereus), and one being an emerging chemical hazard, beauvericin (produced by Fusarium spp.). Cereulide (CER), an emetic toxin of Bacillus cereus, is a lactonic lipophilic dodecadepsipeptide, consisting of 12 stereogenic centres of three repeats of four amino acid residues, acting as a strong potassium selective ionophore.[24] CER is an extremely resistant molecule that retains its toxic activity even after sterilization.[25]

Laboratory Toxins: Polycyclic aromatic hydrocarbons are universal environmental contaminants and get exposed from chemical laboratories and petrochemical industries. Inhalation of aromatic hydrocarbons or hydrocarbons may cause hemorrhaging, craniofacial malformation and cardiac defects, which includes elongated heart and central nervous system toxicities. In laboratories, methanol, petroleum ether, diethyl ether, benzene and acetonitrile are used for extraction and chromatographic separations. [26] The toxicity of methanol and diethyl ether is well established and both the solvent produce toxicity in digestive and nervous systems. Moreover methanol boiling point is around $65 \pm 1^{\circ} \mathrm{C}$ and it is not volatile in ambient temperature. The solvent which have low boiling point (diethyl ether, petroleum ether) are having high risk to produce inhalation toxicity. Inhalation of diethyl ether produce hepatotoxicity and this solvent was not recommended for clinical and pre-clinical experiments.[27] Available toxicity information for some of the laboratory solvent is very limited and it was proven to have CNS toxicity but the pathological features and behavioral alterations induced by petroleum ether are unclear and not reported.

Health effects of laboraotry solvents: The volatile solvents such as petroleum ether, methanol, diethylether, benzene, acetone, ect., are most commonly used in most of the chemcial and pharamcutical industry, which has significnat health effects.

Petroleum Ether: Petroleum ether is one of the most common solvents used in the chemical and pharmaceutical industries/ laboratories. The reported $\mathrm{LD}_{50}$ value of petroleum ether is 3,400 $\mathrm{mg} / \mathrm{l}$ (oral) in 4 hours and the major toxic effect of petroleum ether observed in central nervous and dermatological systems. Since petroleum ether is volatile in normal ambient temperature, and inhalation of petroleum ether gas may cause central nervous, respiratory and digestive systems toxicities. In some laboratory experiments, petroleum ether herbal extract showed piloerection and cannibalism during repeated dose administration. This was not observed in other solvents.

Moreover petroleum ether is reported to have central nervous system toxicity and no data is available on its effect on learning and memory, neuronal and metabolic functions. In our laboratory studies, petroleum ether showed significant loss of memory, cannibalic behaviour and loss of muscular activity in rodents (The data are not published).

Petroleum ether is a group of colorless, volatile liquid with a kerosene-like odor and liquid hydrocarbons with its main use as nonpolar solvents. The chemical properties do not resemble diethyl ether. It is more of a light hydrocarbon.[28] Due to its low flashpoint, a mixture of petroleum ether with air is inflammable and ignites upon contact with hot surfaces. Petroleum ether is largely used in pharmaceutical production and in the manufacturing sector. Its main composition is pentane, and is sometimes replaces pentane due to its lower cost.[28] Petroleum ether has a chemical composition of $80 \%$ pentane and $20 \%$ isohexane.[29] They are the primary constituents with virtually no aromatics present. The Threshold Limit Value (TLV) of petroleum ether is $400 \mathrm{ppm}$. It is the time-weighed average concentration under which people 
can work consistently for 8 hours every day without any harmful effects.[30] Acute poisoning occurs by accidental inhalation of vapors or by inadvertent ingestion. The lethal dose is $7.5 \mathrm{~mL} / \mathrm{kg}$ BW. The lowest lethal concentration by inhalation for human is $3 \mathrm{pph} / 5 \mathrm{~m}$ while the lowest lethal dose by intravenous route for human is $27000 \mathrm{mg} \mathrm{kg}-1$. The $\mathrm{LD}_{50}$ for rats by oral route is more than $5000 \mathrm{mg} \mathrm{kg}^{-1}$. The $\mathrm{LD}_{50}$ for rabbit by topical application is more than $3000 \mathrm{mg} \mathrm{kg}^{-1}$. Uptake by inhalation is actually more dangerous compared to other routes of administration like ingestion. It may cause serious effects like cardiac and respiratory arrest/paralysis and polyneuropathy. Elimination is via the lungs unchanged in unchanged form.[31]

Petroleum ether has many uses and it is used as a component of glues and adhesives. It is also used as a solvent for oils, fats and waxes, as a fuel, in paints and varnishes and in photography.[30] Chlorohydrocarbons has been replaced with petroleum ether in dry cleaning as it is less toxic.[31] It is widely used in lipid extraction as it is a cheaper and less flammable alternative when compared to diethyl ether. As it is highly non-polar, it has the ability to yield more specific extract and only the most non-polar molecules will be obtained.[32]

Methanol: Pure methanol is a colorless liquid, has a specific gravity of 0.81 , a boiling point of $65^{\circ} \mathrm{C}$, and a slight odor distinctly different from that of ethanol. Methanol can be absorbed through the skin, and through the respiratory and gastrointestinal tracts. [33] The current threshold limit value for methanol in industry is $200 \mathrm{ppm}\left(260 \mathrm{mg} / \mathrm{m}^{3}\right)$. There is great variability in the mean lethal dose among animal species. Review of clinical findings in epidemic situations and in isolated cases shows great variation in the dose of methanol required to produce acidosis, blindness, and death.[34] The smallest amount of methanol reported to cause death is $15 \mathrm{~mL}$ of $40 \%$ methanol, the highest dose recorded for a survivor is in the range of 500 to $600 \mathrm{~mL}$. Most cases of severe human poisoning occur by the oral route. Occasional cases occur by skin contact and inhalation. [35]

Methanol is rapidly absorbed from the gastrointestinal tract, with peak absorption occurring in 30 to $60 \mathrm{~min}$ depending on the presence or absence of food in the stomach.[36] The primary site of the ocular injury produced by methanol is in the optic nerve head and the intraorbital portion of the optic nerve, rather than in the retinal ganglia. Hemorrhages into portions of the brain are also an important aspect of methanol poisoning. Cerebral computed tomography in methanol intoxication has shown necrotic areas in the putamen.[37] The putamen may be a specific target for methanol toxicity. Pathological damage to the liver, pancreas and kidneys has also been described but are not specific.

Diethyl Ether: Diethyl ether's creation and use as a solvent, in the production of gum powder, preceding use in the US as an anesthetic and as a primer for gasoline engines result in its discharge to the nature across assorted waste streams. [38] If released to air, an extrapolated vapor pressure of $538 \mathrm{~mm} \mathrm{Hg}$ at $25^{\circ} \mathrm{C}$ indicates diethyl ether will exist merely as a vapor in the ambient atmosphere. Vapor phase diethyl ether will be degraded in the atmosphere by reaction with photochemical-producing hydroxyl radicals and nitrate radicals. Direct photolysis is not anticipated to be a vital removal procedure as aliphatic ethers do not absorb light in the environmental spectrum.

Diethyl ether is anticipated to volatilize from dry dirt surfaces established on its extrapolated vapor pressure. Aqueous screen- ing studies indicate biodegradation is expected to be a slow fate process in both soil and water. Occupational exposure to diethyl ether could transpire across inhalation and dermal contact at workplaces where diethyl ether is produced or used. The general population could be exposed to diethyl ether from inhalation of ambient air, and ingestion of contaminated drinking water. After inhalation, ethyl ether is quickly transferred from alveoli to blood. The normal alveolar membrane poses no barrier to the transfer of ethyl ether in either direction. The blood/gas allocation coefficient of ethyl ether is elevated to 12.1, for oil/gas, the allocation coefficient is 65 .

The solitary dermal penetration $\mathrm{LD}_{50}$ was larger than $20 \mathrm{~mL} / \mathrm{kg}$ in rabbits. The bulk of inhaled ethyl ether is excreted unchanged across the lungs. All volatile anesthetics easily pass through the placental barrier. Diethyl ether is instantaneously absorbed from inhaled air into the bloodstream and from there it travels rapidly into the brain. It is additionally taken up rapidly by fatty tissue in rats. Ether is partly converted to carbon dioxide and to urinary metabolites, but is generally excreted unchanged by the lung. [39]

Benzene: Benzene is an aromatic hydrocarbon and natural constituent of crude oil. Benzene is commonly used for production of ethylbenzene (precursor to styrene), cumene and cyclohexane. The chronic inhalation of the benzene may lead progressively to aplastic anemia, leukaemia and multiple myeloma. Exposure to benzene also can induce micorosomal mixed function oxidase and cytochrome P450 IIE1, which may be responsible for biotransformation of benzene and generating free radicals, which may end with different disease endpoint.[40] In acute exposure, anesthesia may develop at concentration above 3000 ppm $(9,600$ $\left.\mathrm{mg} / \mathrm{m}^{3}\right)$ and exposure of above $1000 \mathrm{ppm}\left(3,200 \mathrm{mg} / \mathrm{m}^{3}\right)$ may cause giddiness, euphoria, nausea, headaches and arrhythmias. $[41,42]$ The hematotoxicity induced by benzene may be mediated through aryl hydrocarbon receptor (AhR). [43]

Benzene is also inducing CYP2E1 activity, thereby increasing toxic metabolite formation, which may be highly toxic. Hydroquinone is one of the metabolic product of benzene, which causes significant structural aberrations in chromosome 1 and 9 probes. [44]In females, benzene causes reproductive, mense-blood anomaly, dysmenorrhea and fetal toxicity. Chronic exposure of benzene leads to development of cytotoxicity, apoptosis, and mutagenesis and cell replication.[45]

Acetone: Acetone is highly volatile, flammable, polar and aprotic solvent and its most commonly used for cleaning purposes in biomedical/ pharmaceutical laboratory. In very low level, no toxicity was observed with acetone and chronic administration/ higher doses in guinea pigs caused reeducation in heart rate, pulmonary congestion, edema and hemorrhage of the lungs and progressively cause mortality. In rodents, acute exposure of acetone cased respiratory depression due to sensory irritation and repeated exposure does not have any effect on the time of inspiration, time of expiration and time between breaths or tidal volume.[46,47] Dietz et al., reported that repeated administration of acetone induced depressed body weight gain (at 50,000 and 100,000 ppm exposed group) and hepatocellular hypertrophy (at 20,000 and 50,000 ppm exposed group) and in mice and mild hematological changes (at 5000 ppm exposed group), hypogonadism (at 50,000 ppm exposed group) in rats. [48] In humans, repeated administration of acetone ( 6 hours exposure for 6 days to $500 \mathrm{ppm}$ ), increased white blood cell counts, increased eosinophil counts and decreased phagocytic activity of neutrophils compared with the 
control. The shortening of menstrual cycle, premature menstrual periods, miscarriage and weakness of labor activity were observed with women who were exposed to workroom level of acetone. $[47]$

Mercury: Mercury and its compounds are highly toxic and this metal that has no biochemical or nutritional value.[49] Inhalation of high levels of mercury vapour may results in central nervous system (CNS) defect.[50,51] Mercury vapour is also causes kidney damage at low level of exposure for prolonged period of time and this effect is also observed in laboratory animals. [50-52] Methyl mercury in diet have been considered as the primary route of exposure and it will accumulate in body tissue, damaging nervous system and methyl mercury can easily cross the blood brain barriers which may lead to development of serious adverse effects especially in childerns. [53] According to Mahaffey et al, mercury also can increase the risk of cardiovascular and heart disease.[55]

\section{Incidences of laboratory accidents with laboratory solvents}

As per the safety expert James A Kaufman stated "schools have a 10 to 50 time's greater frequency of accidents than does the chemical industry. In October 1998, chemistry laboratory has a fire in Cambridge when a researcher accidentally broke a bottle of a flammable solvent hexane and similar hexane issue was observed in Newman-Wolfrom laboratory building, Ohio State University on $8^{\text {th }}$ April 2005.[55-57] The laboratory incident with nitric acid and sulphuric acid was noted in firefighters, paramedics, hazardous material units of University of Maryland on $26^{\text {th }}$ September 2011. The students (11 students) of University of Maryland conducted experiment in firefighters, paramedics, hazardous material units and they combined nitric acid, sulphuric acid and the combine product was introduced into a chemical waste bin. Later a violent chemical reaction occurred causing an explosion with fire and the fire was quickly extinguished and firefighters immediately departed the lab.[58] Sometime the students may not aware about the danger of the experiment and it is supervisor's duty to make clear about the hazards of laboratory solvents and reagents.

The laboratory accidents are not only common in universities. Many of incidents were observed in chemical and pharmaceutical industries. For example, the incidents observed in explosion of fuel blending tank at Chief Supply Corporation (Chief), in Haskell, Oklahoma on March 26, 1997 killed one worker and two others were injured and the explosion had caused extensive damage to the facility.[59]

\section{Reasons for laboratory accidents}

Laboratory is a dangerous place and most of the laboratories are fully stocked with nasty chemicals, solvents, biologicals and equipments. While working in laboratory one should avoid specking, eating, using mobile or personal electronic devices which may communicate with some of the laboratory equipment. Inappropriate personal care and inadequate awareness are major reasons for the majority of unexpected laboratory incidents.

\section{How laboratory accidents can be prevented?}

One can read briefly about prevention of accidents in laboratories is available with Occupational Safety and Health Administration (OSHA) owned by United States Department of Labor (Checklist for the prevention of accidents in laboratories). Laboratory accidents can be prevented by eliminating/ minimizing hazards, evaluation of potential risk, using personal protective equipment, avoid leaving operation unattended and working alone, conducting safety training and inspections and reporting and communication of laboratory accidents. $[60,61]$

1. Training: Before initiating the project, all team members in the project must have to read the laboratory rules and regulation and have to attend the laboratory orientation class to have an overall idea about laboratory work flow and management of unexpected laboratory events. Undergraduate students in the project or regular particle classes may need additional safety training.

2. Limit of purchase and storage: The required chemicals may be purchased based on need or small quantity and try to completely use materials then dispose the empty container safely as direction given by laboratory guideline or handover empty container to laboratory in-charge [Peroxide explosion injures campus researcher]. Storage is very important for any chemicals or solvent. The chemicals, biological and radioactive materials, etc. must be classified and stored according to manufacturer instruction. User should be aware of the nature of the chemical/ solvent, stability, physical properties, first-aid information to prevent any emergences, etc.[62]

\section{Disposal of wastage and elimination of potential haz-} ards: Avoid disposal of any reagent or reaction end product as we like. Sometime disposal of chemical wastage in normal waste bin or hand wash sink may cause explosive reaction and this may cause massive damage to the laboratory. Those who are working in any laboratory they must have adequate knowledge on management of laboratory wastage. Another important thing is disposal of expired chemicals as per the national/ international regulation to prevent disturbance to our ecological system. Using expired chemical is highly dangerous and sometimes this may give path to formation of hazard chemical or gas, which may have greater effect on our ecological system.

4. Monitoring and Reporting: The continuous monitoring and reporting system will reduce the known errors and will create the awareness among the researchers and the laboratory workers. The internal audit system will help the Institute or Industry to improve the safety of laboratory and assure the wellbeing of researchers and laboratory workers.

5. First-aid measures: The laboratory must have adequate aeration/ air circulation system, water facilities, water sprinkler, fire alarm system, valid fire extinguisher, emergency exit and access control system. Another major measure is "AVOID WORKING ALONE IN LABORATORY" to prevent any medical or laboratory emergency.

\section{References}

[1]. Kaukiainen A, Vehmas T, Rantala K, Nurminen M, Martikainen R, et al. (2004) Results of common laboratory tests in solvent-exposed workers. Int Arch Occup Environ Health 77(1):39-46.

[2]. Lundberg I, Nise G, Hedenborg G, Högberg M, Vesterberg O. (1994) Liver function tests and urinary albumin in house painters with previous heavy exposure to organic solvents. Occup Environ Med 51(5):347-53.

[3]. Dubey AK (2010). "Bhopal Gas Tragedy: 92\% injuries termed "minor"". First14 News. http://www.first14.com/bhopal-gas-tragedy-92-injuriestermed-minor-822.html .

[4]. Eckerman I. Chemical Industry and Public health Bhopal as an example (MPH 2001: 24). http://www.lakareformiljon.org/images/stories/dokument/2009/bhopal_gas_disaster.pdf

[5]. Bhopal disaster. http://en.wikipedia.org/wiki/Bhopal_disaster\#cite_notefirst3-7 
[6]. Chlorofluorocarbon. http://www.theozonehole.com/cfc.htm.

[7]. Chlorofluorocarbon http://en.wikipedia.org/wiki/Chlorofluorocarbon.

[8]. Toxins, Public health response to biological and chemical weapons-WHO guidance. http:/ / www.who.int/csr/delibepidemics/en/annex2.pdf.

[9]. Production and stockpiling of bacteriological (biological) and toxin weapons, second review conference of the parties to the convention on the prohibition of the development. Geneva, United Nations, 1986. http://www. un.org/disarmament/WMD/Bio/.

[10]. Koch BL, Edvinsson AA, Koskinen LO (1999) Inhalation of substance P and thiorphan: acute toxicity and effects on respiration in conscious guinea pigs. J Appl Toxicol 19(1):19-23.

[11]. Novel toxins and bioregulators. Ottawa, Ministry of External Affairs and International Trade, 1991.

[12]. Joshi BS, Kaul PN (2001) Alternative medicine: Herbal drugs and their critical appraisal part 1 Progress in Drug Research 56: 1-76.

[13]. Bateman J, Chapman RD, Simpson D. (1998) Possible toxicity of herbal remedies. Scott Med J 43(1):7-15.

[14]. Deng JF, Lin TJ, Kao WF, Chen SS (1997) The difficulty in handling poisonings associated with Chinese traditional medicine: a poison control center experience for 1991-1993. Vet Hum Toxicol 39(2):106-14.

[15]. Pritchard JF, Jurima-Romet M, Reimer ML, Mortimer E, Rolfe B, Cayen MN (2003) Making better drugs: Decision gates in non-clinical drug development. Nat Rev Drug Discov 2(7):542-53.

[16]. Wang Y, Li Y, Ding J, Jiang Z, Chang Y (2008) Estimation of bioconcentration factors using molecular electro-topological state and flexibility. SAR QSAR Environ Res 19(3-4):375-95.

[17]. Zhang HX, Li Y, Wang X, Wang YH (2012) Probing the structural requirements of A-type Aurora kinase inhibitors using 3D-QSAR and molecular docking analysis. J Mol Model 18(3):1107-22.

[18]. Butina D, Segall MD, Frankcombe K (2002) Predicting ADME properties in silico: methods and models. Drug Discov Today 7(11):S83-8.

[19]. Huang R, Southall N, Xia M, Cho MH, Jadhav A, et al. (2009). Weighted feature significance: a simple, interpretable model of compound toxicity based on the statistical enrichment of structural features. Toxicol Sci 112(2):385-93.

[20]. EFSA Scientific report of EFSA and ECDC: The European Union Summary Report on Trends and Sources of Zoonoses, Zoonotic Agents and Foodborne Outbreaks in 2009. (2011) EFSA Journal 9(3):2090.

[21]. EFSA Scientific report of EFSA and ECDC: The European Union Summary Report on Trends and Sources of Zoonoses, Zoonotic Agents and Foodborne Outbreaks in 2010. ( 2011) EFSA Journal 9:2090.

[22]. EFSA The community summary report on trends and sources of zoonoses and zoonotic agents in the European Union in 2007, EFSA Journal, 2009L:223.

[23]. Logan NA (2012) Bacillus and relatives in foodborne illness. J Appl Microbiol 112(3):417-29.

[24]. Ceuppens S, Rajkovic A, Heyndrickx M, Tsilia V, Van De Wiele T, (2011) Regulation of toxin production by Bacillus cereus and its food safety implications. Crit Rev Microbiol 37(3):188-213.

[25]. Rajkovic A, Uyttendaele M, Vermeulen A, Andjelkovic M, Fitz-James I, et al. (2008) Heat resistance of Bacillus cereus emetic toxin, cereulide. Lett Appl Microbiol 46(5):536-41.

[26]. Tiem V, Anne L. (2011) Molecular Mechanisms of Polycyclic Aromatic Hydrocarbon-induced Teratogenesis in Zebrafish (Danio rerio). http:// dukespace.lib.duke.edu/dspace/handle/10161/5705;Articel

[27]. Stevens WC, Eger EI, White A, Halsey MJ, Munger W, et al (1975) Comparative toxicities of halothane, isoflurane, and diethyl ether at subanesthetic concentrations in laboratory animals. Anesthesiology 42(4):408-19.

[28]. Williamson K. (2004) Organic Experiments. 9th ed. Boston: Houghton Mifflin Company.

[29]. United States: Centers for Disease Control and Prevention; 1977. http:// www.cdc.gov/niosh/pdfs/77-192b.pdf, last accessed on 5/6/13

[30]. Kent C. (1998) Basics of toxicology. John Wiley \& Sons p .195.

[31]. Reichl FX, Ritter L. (2010) Illustrated Handbook of Toxicology. Germany: Thieme.

[32]. Bergeron F, Benning M. Comparison of Two Fat Extraction Methods. http://web2.slc.qc.ca/jmc/www/Chemweb/oldchemweb/extractionmethods.htm,

[33]. McMartin KE, Ambre JJ, Tephly TR. (1980) Methanol poisoning in human subjects. Role for formic acid accumulation in the metabolic acidosis. Am J Med 68(3):414-8.
[34]. Naraqi S, Dethlefs RF, Slobodniuk RA, Sairere JS. (1979) An outbreak of acute methyl alcohol intoxication. Aust N Z J Med 9(1):65-8.

[35]. Chinard FP, Frisell WR. (1976) Methanol intoxication: biochemical and clinical aspects. J Med Soc N J 73(9):712-9.

[36]. Baumbach GL, Cancilla PA, Martin-Amat G, Tephly TR, McMartin KE, et al. (1977) Methyl alcohol poisoning. IV. Alterations of the morphological findings of the retina and optic nerve. Arch Ophthalmol 95(10):1859-65.

[37]. Martin-Amat G, McMartin KE, Hayreh SS, Hayreh MS, Tephly TR. (1978) Methanol poisoning: ocular toxicity produced by formate. Toxicol Appl Pharmacol 45(1):201-8.

[38]. NEG and NIOSH basis for an occupational health standard. www.cdc.gov/ niosh/docs/96-104/pdfs/96-104.pdf.

[39]. NEG and NIOSH basis for an occupational health standard, Ethyl ether US department of health and human services. http://www.cdc.gov/niosh/ docs/93-103/pdfs/93-103.pdf.

[40]. Yardley-Jones A, Anderson D, Parke DV. (1991) The toxicity of benzene and its metabolism and molecular pathology in human risk assessment. Br J Ind Med 48:437-44.

[41]. Snyder R, Hedli CC. (1996) An overview of benzene metabolism. Environ Health Perspect 104(1 6): 1165-1171.

[42]. Determination of Acute Reference Exposure Levels for Airborne Toxicants. Acute toxicity summary of Benzene. Available in http://oehha.ca.gov/air/ acute_rels/pdf/71432A.pdf.

[43]. Yoon BI, Hirabayashi Y, Kawasaki Y, Kodama Y, Kaneko T, et al. (2002) Aryl hydrocarbon receptor mediates benzene-induced hematotoxicity. Toxicol Sci 70(1):150-6.

[44]. Eastmond DA, Rupa DS, Hasegawa LS. (1994) Detection of hyperdiploidy and chromosome breakage in interphase human lymphocytes following exposure to the benzene metabolite hydroquinone using multicolor fluorescence in situ hybridization with DNA probes. Mutat Res 322:9-20.

[45]. Toxicological review of benzene. US Environmental protection agency, Washington DC. http://www.epa.gov/iris/toxreviews/0276tr.pdf.

[46]. Schaper M, Brost MA. (1991) Respiratory effects of trimellitic anhydride aerosols in mice. Arch Toxicol 65(8):671-7.

[47]. Toxicological profile for acetone, U.S. Department of health and human services (May 1994). http://www.atsdr.cdc.gov/toxprofiles/tp21.pdf.

[48]. Dietz DD, Leininger JR, Rauckman EJ, Thompson MB, Chapin RE, et al. (1991). Toxicity studies of acetone administered in the drinking water of rodents. Fundam Appl Toxicol 17(2):347-60.

[49]. World Health Organisation (1989b) Mercury Evironmental Health Criteria 86 ISBN 9241542861

[50]. ASTDR (2000) Toxicological profile for cadmium. Agency for Toxic Substances and Disease Registry

[51]. Goyer, R.A (1996) Toxic effects of metals. In Casarett and Doull's Toxicology. The Basic Science of Poisons, Fifth Edition, Klaassen,C.D.[Ed] Mc.Graw Hill Health Professions Division, ISBN0071054766

[52]. Ratcliffe H.E,Swanson G.M, Fisher L.J (1996) Human exposure to mercury: a critical assessment on the evidence of adverse effects. Journal of Toxicology and Environmental Health 49:221-270

[53]. UNEP(2002) Global Mercury Assessment, United Nations Environmental Programme (UNEP) Chemicals, Geneva, Switzerland. http://www.unep. org/gc/gc22/Document/UNEP-GC22-INF3.pdf

[54]. Mahaffey K.R,Clicknerr RP, Budorrow C.C (2004) Blood Organic Mercury and Dietary Mercury Intake: National Health and Nutrition Examination Survey, 1999 and 2000. Environmental Health Prespectives 112(5):562-570

[55]. Laboratory fire caused by the solvent hexane [Massachusetts Institute of Technology] . http://web.mit.edu/newsoffice/1998/fire-1028.html

[56]. Fighting lab fires. http://pubs.acs.org/cen/news/83/i21/8321ohio.html

[57]. Fire damages chemistry lab. http:// newsoffice.mit.edu/1998/fire-1028

[58]. Something Went Wrong in CHEM 242 Class. http://pgfdpio.blogspot. $\mathrm{com} / 2011 / 09 /$ university-of-maryland-chemical.html

[59]. Prevention of reactive chemical explosion. http://www.epa.gov/osweroe1/ docs/chem/chiefinl.pdf

[60]. Checklist for the prevention of accidents in laboratories. https://osha.europa.eu/en/publications/e-facts/efact20.

[61]. How can I prevent laboratory accidents? http://science.widener.edu/svb/ olcc_safety/papers/benedict.pdf

[62]. Peroxide explosion injures campus researcher. https://www.ehs.uci.edu/ salerts/Lesson\%20Learned_Peroxide.pdf 